\title{
Processing Topics from the Beneficial Cognitive Model in Partially and Over-Successful Persuasion Dialogues
}

\author{
Kamila Debowska-Kozlowska
}

Published online: 19 July 2014

(C) The Author(s) 2014. This article is published with open access at Springerlink.com

\begin{abstract}
A persuasion dialogue is a dialogue in which a conflict between agents with respect to their points of view arises at the beginning of the talk and the agents have the shared, global goal of resolving the conflict and at least one agent has the persuasive aim to convince the other party to accept an opposing point of view. I argue that the persuasive force of argument may have not only extreme values but also intermediate strength. That is, I wish to introduce two additional types of the effects of persuasion in addition to successful and unsuccessful ones (cf. Van Eemeren and Houtlosser in Argumentation 14(3):293-305, 2000; Advances in pragma-dialectics. Sic Sat, Amsterdam, 2002; Walton in A pragmatic theory of fallacy. University of Alabama Press, Tuscaloosa, 1995; Walton and Krabbe in Commitment in dialogue: basic concepts of interpersonal reasoning. State University of New York Press, Albany, New York, 1995). I propose a model which provides for modified versions of the standpoint of an agent needed in order to bring about two possible outcomes of a persuasion dialogue. These two outcomes I label partially-successful and over-successful. I call the potential, not yet verbalised, standpoint of an agent here the original topic t. Based on some aspects of relevance theory (Sperber and Wilson in Relevance: communication and cognition. Blackwell, Oxford, 1986; Wilson and Sperber in The handbook of pragmatics. Blackwell Publishing, Malden, 2006), I explain that the modified version of the original topic $t$ is an implicature created from the original topic $t$ and from a specific mental topic which belongs to, what I call the beneficial cognitive model (hence BCM). I define BCMi,t as a set of topics which are within the area of agent i's interest of persuasion with respect to $t$.
\end{abstract}

A comment to this article is available at doi:10.1007/s10503-014-9317-3.

K. Debowska-Kozlowska ( $₫)$

Department of Pragmatics of English, Faculty of English, Adam Mickiewicz University, al.

Niepodleglosci 4, 61-874 Poznan, Poland

e-mail: kamila@wa.amu.edu.pl 
Keywords Persuasion - Persuasive force of argument - Success - Goal - Relevance theory $\cdot$ Mental topic $\cdot$ Cognition

\section{Introduction}

Actual communication practice is the point of departure for the model presented in this paper. The paper is rooted in the programme of the Polish School of Argumentation which is inspired by the pragma-linguistic and cognitive aspects (see Kopytko 2002; Cap 2010) of argument force in communication practice. This paper proposes to consider a specific type of dialogue called a persuasion dialogue in which two participants have opposing points of view on a certain issue. The notion of a point of view is defined here in pragma-dialectical terms and is described as "a certain positive or negative position with respect to a proposition" (van Eemeren 2001: 17). Participants in this specific type of dialogue act as proponent and opponent. A proponent of a particular point of view adopts a positive position with respect to a certain proposition. The opponent of the point of view challenges the positive position of the proponent or expresses a counter attitude to that position. If the opponent only questions the proponent's position, without defending a thesis of his own, then he becomes engaged in a non-mixed dispute. If the opponent expresses his own position with respect to a proposition, then he becomes involved in a mixed dispute (van Eemeren and Grootendorst 1992: 17). In this article, the proponent and the opponent are named agent $i$ and agent i' respectively.

I define a persuasion dialogue as a dialogue in which a conflict between agents with respect to their points of view arises at the beginning of the talk and the agents have the shared, global goal of resolving the conflict. Furthermore, as part of this definition, at least one agent has the persuasive aim to convince the other party to accept an opposing point of view (cf. Walton 1995; Walton and Krabbe 1995). I claim that an agent has a persuasive aim if he is interested only in such an outcome of a dialogue in which his position wins. My perspective on persuasion relies on its socio-psychological definition which treats it as "a successful intentional effort at influencing another's mental state through communication" (O'Keefe 2002: 5).

The main aim of this paper is to introduce a supplementary model which distinguishes types of persuasion effects in addition to the ones discussed in the pragma-dialectical critical discussion (van Eemeren and Houtlosser 2002; van Eemeren 2009) and the Waltonian persuasion dialogue (1995; Walton and Krabbe 1995). Both of those approaches allow the analyst to identify two types of effects: fully successful persuasion and fully unsuccessful persuasion. They propose systems describing the course of a dialogue in which the standpoint of an agent is introduced in advance and is not changed during the dialogue. The term "standpoint" is considered here in pragma-dialectical terms. "Standpoint" is defined as "(...) individual expression of someone's subjective opinion (...), a public statement put forward for acceptance by a listener or reader who is assumed not to share the speaker or writer's point of view" (Houtlosser 2001: 31).

The model I propose here provides for modified versions of the standpoint of an agent during one dialogue and introduces two additional types of effects of 
persuasion: partially successful dialogue and over-successful dialogue (cf. Budzynska and Debowska 2010). ${ }^{1}$ The normative reason for adding these two nuances of success is to give the proponent his due after he has partially or excessively made his case. I claim that a certain mental conception in the mind of an agent, which I call in this paper the original topic $t$, might become his standpoint when publicly expressed in a persuasion dialogue. ${ }^{2}$

The secondary aim of the paper is to see how a certain modified version of the original topic $\mathrm{t}$ is generated in the mind of an agent and why that version of topic $\mathrm{t}$ has a decisive function in describing partially successful persuasion and oversuccessful persuasion. Based on some aspects of relevance theory (Sperber and Wilson 1986; Wilson 1994, 2000; Wilson and Sperber 2006), I explain that the modified version of the original topic $t$ is an implicature created from the original topic $\mathrm{t}$ and from a specific mental topic which belongs to, what I call the beneficial cognitive model (hence BCM). ${ }^{3}$ I define BCMi,t as a set of "beneficial" topics with respect to $t$ which are within the area of agent i's interest of persuasion.

The paper is structured as follows. Section 2 shows how the persuasive aim is considered in the models of the pragma-dialectical critical discussion and Waltonian persuasion dialogue, and what type of a criterion is provided by those models to evaluate the persuasive force of argument in terms of its successfulness. The paper also seeks to show that the criterion of acceptance or rejection of an agent's point of view by the other party does not apply to the assessment of dialogues in which types of persuasion other than those fully successful or fully unsuccessful are intuitively recognised. Section 3 elaborates on the notion of topic $t$ and introduces the notion of the set of other topics $\mathrm{Ti}, \mathrm{t}=\{\mathrm{t} 1, \ldots, \mathrm{tn}\}$ which helps agent $\mathrm{i}$ resolve the difference between his and the other party's point of view. Using the aspects of relevance theory, Sect. 3 shows how the set of other topics Ti,t $=\{\mathrm{t} 1, \ldots, \mathrm{tn}\}$ is activated in the mind of agent i during a dialogue. Section 4 explains that the BCM is a subset of $\mathrm{Ti}, \mathrm{t}$, but involves only the topics which help agent i realise his persuasive intention. Section 5 shows that only the topics from BCMi,t might help to generate the modified version of topic $\mathrm{t}$ needed for obtaining partially-successful and oversuccessful persuasion dialogues. Finally, Sect. 6 discusses some selected features of partially-successful and over-successful persuasion dialogues.

\section{Persuasive Aim in the Standard Models}

The representatives of the pragma-dialectical school of argumentation (van Eemeren and Houtlosser 2002; van Eemeren 2009) and Walton (1995; Walton

\footnotetext{
1 In (Budzynska and Debowska 2010), I discuss over-success in the case of dialogues with conflict resolution using the notions of 'degree of importance' and 'degree of acceptance'.

${ }^{2}$ Clearly, a mental conception of topic $t$ cannot be evaluated as true or false or acceptable or unacceptable because it functions only as a proposition under consideration. However, when it becomes verbalised in the form of a statement it might be evaluated in this way.

3 See (Budzynska and Witek 2014) for another example of a pragmatic approach to argumentation. While my approach relies on relevance theory, theirs relies on the theory of speech acts.
} 
and Krabbe 1995) discuss the persuasive aim ${ }^{4}$ of an agent and provide a criterion for its successful achievement. In the pragma-dialectical advanced model of a critical discussion, the persuasive aim is discussed in relation to the dialectical aim. Van Eemeren and Houtlosser (2000, 2002; van Eemeren 2009, see also Debowska et al. 2009: 122-123) introduce the concept of 'strategic manoeuvring' when discussing the employment of reasonable argumentation achieved by maintaining a balance between the simultaneous pursuit of the persuasive and dialectical aim. Pragmadialecticians indicate that disputants may simultaneously pursue the persuasive aim of making the strongest case and the dialectical aim of the resolution of the difference of opinion. In pragma-dialectics, a persuasive aim is concerned with the intention of an individual agent to have his own point of view accepted. As van Eemeren and Houtlosser (2002:15) emphasise, "rhetorical considerations [in a critical discussion] relate to the contextual adjustment of argumentation to the people that are to be convinced".

Walton (1995), Walton and Krabbe (1995) discuss the persuasive aim of an agent within the model of a persuasion dialogue and relate it to the notion of commitments (cf. Kacprzak and Yaskorska, this issue). They indicate that the individual aim of each agent in this type of dialogue is "to persuade others to take over its point view" (Walton and Krabbe 1995: 68). Walton (1995: 18-19) treats a critical discussion as a subspecies of a persuasion dialogue. As Walton (1995: 100) indicates, "the critical discussion is a much more specific and precisely regulated type of dialogue [than a persuasion dialogue] that has all kinds of specific rules defining what a participant may or may not do at any given stage [of the dialogue]". The Waltonian model centres on the commitments of the other party. Commitments are said to be ascribed to propositions when an agent publicly declares them as his beliefs, attitudes, intentions, plans, preferences, etc. (cf. Walton 1995; Searle 1970; Hamblin 1970; Katriel and Dascal 1989; van Eemeren and Grootendorst 1984, 2004; van Eemeren and Houtlosser 2004). Walton (1995) emphasises that an agent realises his persuasive aim by trying to determine what will successfully persuade the other party by tracking the other party's commitments.

In both the pragma-dialectical model of a critical discussion and the Waltonian model of a persuasion dialogue, the acceptance or rejection of an agent's point of view by the other party is a criterion for deciding whether persuasion has been successful or unsuccessful. If the opponent changes his point of view or his stance towards the proponent's thesis at the end of the dialogue, then persuasion is evaluated as successful for the proponent. If at the end of the dialogue the opponent does not change his point of view or his stance towards the proponent's thesis, then persuasion is evaluated as unsuccessful for the proponent.

Below I present two brief examples of dialogue 1 and 2 to show that the criterion provided by the standard models permits the identification of fully successful persuasion and fully unsuccessful persuasion but not the nuances of partially

\footnotetext{
${ }^{4}$ See (Castelfranchi and Paglieri 2007) for the cognitive processing of a goal in which beliefs and desires are perceived as pre-stages.
} 
successful and over-successful persuasion. ${ }^{5}$ Since dialogue 1 and $2^{6}$ are to serve as quick ways of showing what I mean by partial and over-success there is not too much elaboration of their argumentative content.

Consider dialogue 1 in which partially successful persuasion is intuitively observed:

John_1 Please lend me a 100 euro note.

Ann_2 No, I can't. I have got only a 50 euro note.

John_3 OK, in that case I can take 50 euros.

Ann_4 OK.

Intuitively, partially successful persuasion has been achieved in dialogue 1 because John has not persuaded Ann to lend him 100 euros, but he will get part of the amount he wanted. The proposition which John defends in move John_1 can be reconstructed as "You should give me a 100 euro note". Move John_1 can also be read as a full argument: "You should give me a 100 euro note, because I need 100 euros and you possibly have a 100 euro note". The proposition defended by John in move John_3 is "You should give me a 50 euro note". Turn 3 can also be read as a full argument "You should give me a 50 euro note, because I need 50 euros and you have a 50 euro note." Relying on standard models of conflict resolution we cannot, however, describe this type of dialogue as partially successful persuasion. Pragmadialecticians would probably reconstruct the dialogue as a multiple dispute in which two standpoints are defended and one of these ("I think you should give a 100 euro note") is abandoned at some point, and the second one (i.e. "I think you should give me a 50 euro note") is won by John. From the Waltonian perspective, the dialogue might be considered a situation where John comes up with a new standpoint (i.e. "I think you should give me a 50 euro note") at some point in the dialogue, and instead of retracting the earlier thesis (i.e. "You should give a 100 euro note"), he starts defending the new thesis.

Even if only one standpoint were considered by pragma-dialectians and Walton (i.e. "I think you should give a 100 euro note") in the reconstruction of dialogue 1, then still the pragma-dialectical and Waltonian criterion of achieving success by convincing the other party to accept the opposing point view would not be fulfilled. Ann has not been persuaded to give John a 100 euro note. Since John has not achieved his original aim of borrowing a 100 euro note, the dialogue would be evaluated as a fully unsuccessful persuasion. Still, it is not true that John has gained

\footnotetext{
${ }^{5}$ Numerical representation of the degrees of achieving success has already been discussed by Budzynska and Kacprzak (2008), Budzynska and Kacprzak (2011), but this paper focuses on non-numerical representation.

${ }^{6}$ Looking at the surface structure of dialogue 1 and 2, it is possible to point out in those dialogues the features of a negotiation dialogue and the features of a persuasion dialogue. Relying exclusively on the surface structure of dialogue 1 and 2 it is, therefore, possible to analyse those dialogues in terms of Walton (1995) mixed dialogues. My aim at this point is, however, to use those dialogues as simple cases for showing what I mean by partial and over-success. Additionally, it should also be noticed that no conflict of interest is present in those dialogues; therefore, they could not be reconstructed as pure cases of a negotiation dialogue. It is the conflict of opinion which allows to reconstruct those dialogues as a persuasion dialogue.
} 
nothing. After all, he has convinced Ann of a thesis that seem to be closely related to his initial thesis.

Consider dialogue 2 in which over-successful persuasion is intuitively observed:

John_1 Please lend me 100 euros.

Ann_2 No, I can't. I have got only a 200 euro note.

John_3 OK, in that case I can take 200 euros.

Ann_4 OK.

Intuitively, over-successful persuasion has been achieved in dialogue 2 because John has achieved more than he has wanted, in the sense that he convinced Ann of his initial thesis and, additionally, he convinced her of the thesis that seem to be closely related to his initial one. The proposition which John defends in move John_1 can be reconstructed as "You should give me a 100 euro note". Move John_1 can also be read as a full argument: "You should give me a 100 euro note, because I need 100 euros and you possibly have a 100 euro note". The proposition defended by John in move John_3 is "You should give me a 200 euro note". Turn 3 can also be read as a full argument: "You should give me a 200 euro note, because I need 200 euros and you have a 200 euro note." Using the standard models, we cannot, however, conclude that John has obtained more than he has expected. Again, pragma-dialecticians would probably reconstruct the dialogue as a multiple dispute in which two standpoints are defended and one of these ("I think you should give a 100 euro note") is abandoned at some point, and the second one (i.e. "I think you should give me a 200 euro note") is won by John. From the Waltonian perspective, it might be recognised as a situation where John comes up with a new standpoint (i.e. "I think you should give me a 200 euro note") at some point in the dialogue, and instead of retracting the earlier thesis (i.e. "You should give a 100 euro note"), he starts defending the new thesis.

Even if only one standpoint were considered by pragma-dialectians and Walton (i.e. "I think you should give a 100 euro note") in the reconstruction of dialogue 2 , then we could only evaluate whether or not Ann has been convinced to accept this initial topic, i.e., that she should give John 100 euros. In such a reconstruction, the criterion of achieving full success would be fulfilled and therefore the persuasion would be evaluated as fully successful rather than over-successful, even though John has gained more money than he has asked for.

\section{Notions of Topic, Manifestness and Implicature}

In this article, I define the term 'topic' as a mental conception in the mind of agent $\mathrm{i}$ or agent i' which might become any statement, e.g., an assertion, a question, a standpoint or an argument, when it is publicly expressed. Therefore, the term 'topic' does not relate here to the Aristotelian notion of topos (Aristotle 1955; 1959) or Perelman and Olbrechts-Tyteca (1969)'s notion of 'locus' which focus on rules and instructions for creating a link between a standpoint and an argument (c.f. Garssen 2001; Rigotti 2007; Rigotti and Morasso 2010). 
I introduce here a distinction between topic $t$ and other topics (i.e. $t 1, t 2, t 3, t 4, \ldots$, tn) which might be activated in the mind of agent $i$ during a persuasion dialogue (see e.g. Kacprzak and Yaskorska (2014, this issue) for the formal way of describing dialogues). Topic $\mathrm{t}$ relates throughout the paper to a potential standpoint. As mentioned in the introduction, the term 'standpoint' is considered here in pragmadialectical terms. The term 'potential' is applied here to the description of the notion of standpoint because it does not refer to a verbalised notion. In other words, the term 'potential' means that topic t does not become a real standpoint until certain commitments are ascribed to it. Thus, topic t is considered a potential, not a real, standpoint until certain preferences or attitudes with reference to it are publicly declared by agent $i$.

It is assumed in the article that a certain mental topic from the set Ti,t needs to be activated in the mind of agent $i$ to contribute to generating a modified version of topic t. Relying on the elements of relevance theory introduced by Sperber and Wilson (1986; Wilson 1994, 2000; Wilson and Sperber 2006, cf. Yus 2006, see also Walaszewska and Piskorska 2012), I describe below two stages needed for the activation of a certain mental topic in the mind of agent i. Two notions from relevance theory are used for the description of the stages: cognitive environment and manifestness. Subsequently, it is explained how an implicature is created in the mind of agent $\mathrm{i}$ after the activation of the topic from the set Ti,t.

The first stage relates to the expression of an utterance. Agent i needs to hear an utterance to activate a certain mental topic in his mind. According to relevance theory, every utterance communicates certain facts and assumptions. After hearing an utterance, agent $\mathrm{i}$ adds the facts and assumptions from the utterance to his cognitive environment. The relevance-theoretic notion of the cognitive environment pertains to the set of those facts and assumptions which the hearer has possessed before a dialogue has started and those which have become available to him during the dialogue. The cognitive environment involving the set of old facts and assumptions is treated as the integrated context which helps agent $\mathrm{i}$ better understand the new information. Particular pieces of the information belonging to the cognitive environment of agent $\mathrm{i}$ are manifest to him in different degrees, e.g., they might be even less than known or assumed to him. An advocate of relevance theory, Carston (2002: 378), defines manifestness of an assumption to an individual as "the degree to which an individual is capable of mentally representing an assumption and holding it as true or probably true at a given moment". Agent i must accept a new assumption as true or probably true to adopt it and add it to his cognitive environment as a manifest assumption.

The second stage refers to the process of activation of a certain topic from the set $\mathrm{Ti}, \mathrm{t}=\{\mathrm{t} 1, \ldots, \mathrm{tn}\}$ by a manifest assumption. Topics from the set Ti,t $=\{\mathrm{t} 1, \ldots, \mathrm{tn}\}$ are assumed to be part of the cognitive environment and therefore to have a manifest status as well. Manifestness of a topic from the set Ti,t is defined here as the degree to which an agent $i$ is capable of mentally representing the topic and accepting it as true or probably true. I argue that topic $\mathrm{t}$ and topics $\mathrm{t} 1, \mathrm{t} 2, \mathrm{t} 3, \mathrm{t} 4, \ldots$, tn from the set $\mathrm{Ti}, \mathrm{t}$ are already present in the cognitive environment of agent $\mathrm{i}$ before a dialogue starts or become part of it during the dialogue. The cognitive environment of agent $i$ consists not only of the topics he is aware of, i.e. topics which he knows are 
advantageous to him because they help him resolve the conflict, but also of the topics he might become aware of during the dialogue (for example, when raised by the opposing agent i') if his cognitive abilities allow for it. $^{7}$ If the manifest assumption added to the cognitive environment is identical or similar to a certain manifest topic from the cognitive environment, then the manifest assumption activates the certain manifest topic in the mind of agent $i$.

In a persuasion dialogue, the first, most accessible interpretation of the expressed utterance called an implicature is created in the mind of agent $i$. This interpretation comes about by two processes: (1) the creation of a specific manifest assumption in the mind of agent $i$ and (2) the activation of a topic from the set Ti,t in the mind of agent $i$. Also, the fact that agent $i$ is aware of his standpoint contributes to the emergence of the implicature from the expressed utterance. Sperber and Wilson (1986: 194-195) define an implicature ${ }^{8}$ as "a contextual assumption or implication which a speaker, intending her utterance to be manifestly relevant, manifestly intended to make manifest to the hearer". An important aspect of the process of drawing an implicature in a persuasion dialogue is the fact that the process helps agent $\mathrm{i}$ realise whether an expressed utterance yields to his persuasive advantage. Section 4 shows which activated topics from the set Ti,t help agent i realise his persuasive intention.

\section{Beneficial Cognitive Model (BCM) as Part of a Cognitive Environment}

As explained in Sect. 3, the set Ti,t is a set of topics which are advantageous for agent $i$ since they help agent $i$ resolve the difference of opinion. In other words, the set of topics $\mathrm{Ti}, \mathrm{t}=\{\mathrm{t} 1, \ldots, \mathrm{tn}\}$ consists of topics which help agent $\mathrm{i}$ resolve the conflict no matter whether he has a persuasive or collaborative or any other individual aim. I argue that the BCM is part of the set Ti,t. I define BCMi,t as a set of beneficial topics which help agent i resolve the conflict of opinion but only in his favour. In other words, topics from BCMi,t help agent i fulfil only his persuasive aim. Cognitive environment (i.e. CE) is thus a broader conception than the set Ti,t and the set Ti,t is a broader conception than BCMi,t, i.e. BCMi,t $\subset$ Ti,t $\subset \mathrm{CE}$.

\footnotetext{
7 The set $\mathrm{Ti}, \mathrm{t}=\{\mathrm{t} 1, \ldots, \mathrm{tn}\}$ considered in this paper might appear to be close to what van Eemeren et al. (1993) call disagreement space. Van Eemeren et al. (1993) discuss disagreement space by means of Searle's correctness conditions for speech acts. In contrast, the set $\mathrm{Ti}, \mathrm{t}=\{\mathrm{t} 1, \ldots, \mathrm{tn}\}$ is not in any way concerned with the propriety of speech acts in a persuasion dialogue. The set $\mathrm{Ti}, \mathrm{t}=\{\mathrm{t} 1, \ldots, \mathrm{tn}\}$ refers to a set of mental topics in the mind of a proponent which might become any speech acts when publicly expressed but need to belong to proponent's interest of conflict resolution.

8 The Gricean view and relevance theory differ in their approaches to the number of stages needed for implicature's recognition. Grice $(1975,1989)$ presents a two-stage approach to implicature's recognition. According to him, only after the literal meaning is decoded in the mind of the hearer of an utterance is the implicature communicated by the speaker recognised. Relevance theory rejects the Gricean view and proposes to perceive the process of implicature recognition as one stage. According to relevance theory's Cognitive Principle of Relevance, "human cognition tends to be geared to maximization of relevance" (Wilson and Sperber 2006: 610). The principle states that a hearer attempts to maximize the relevance of an expressed utterance and thus considers it in a way which involves the least processing effort from him. Therefore, a hearer of an utterance arrives at its intended meaning ('an implicature') without prior processing of its literal meaning.
} 
Not all topics from a Ti,t are thus equally satisfying for agent $\mathrm{i}$ in terms of his persuasive aim. I propose to call the topics belonging only to the BCMi,t and therefore involving the satisfying, advantageous, salient and essential points for agent $\mathrm{i}$ in terms of his persuasive wants and desires prototype topics and the topics which are not advantageous for agent $\mathrm{i}$ in terms of his persuasive wants and desires radial topics. The set of topics $\mathrm{Ti}, \mathrm{t}=\{\mathrm{t} 1, \ldots, \mathrm{tn}\}$ consists thus of prototype and radial topics. BCMi,t includes only prototype topics. The inspiration for the use of the terms 'prototype' and 'radial' comes from Lakoff (1987). The topics from a BCM are not, however, in any way concerned with Lakoff's idea of categorization of concepts having some universal features. Topics are prototype or radial in terms of individual gains of agent $\mathrm{i}$ during a persuasion dialogue involving a conflict of opinions.

\section{Defining Partially and Over-Successful Persuasion Dialogues}

In this section I propose a definition of a partially successful persuasion dialogue and an over-successful persuasion dialogue. The definitions are provided below:

Partially successful persuasion dialogue for topic $t$ and agent $i-$ a persuasion dialogue in which agent $i$ and the opposing agent i' do not agree on the original topic $\mathrm{t}$ but agree on the version of topic $\mathrm{t}$ which is logically implied by the original topic t or pragmatically implicated by the implicit warrant of agent i's argument and is generated by the implicature which arises from both $t$ (i.e. the original standpoint of agent i) and the activated prototype topic from BCMi,t.

Over-Successful persuasion dialogue for topic $t$ and agent $i-a$ persuasion dialogue in which agent $i$ and the opposing agent i' agree on the original standpoint and the version of topic $t$ generated by the implicature which arises from both $t$ (i.e. the original standpoint of agent i) and the activated prototype topic from BCMi,t. The version of topic $\mathrm{t}$ (the new standpoint) logically implies the truth of the original standpoint.

The pragmatic implication refers in the first definition to accepting the implicit warrant of proponent's argument by an opponent. The version of topic t discussed in the definitions is treated as a qualified standpoint because in the course of a dialogue it becomes a variation (a modified version) of the original standpoint on which agents agree. In the case of a partially successful persuasion dialogue and an oversuccessful persuasion dialogue, the qualified standpoint is generated by an implicature arising from the original standpoint of agent $i$ and a prototype topic from the BCM of agent i. In partially successful persuasion only a qualified standpoint needs to be accepted. In over-successful persuasion, both the original and qualified standpoints need to be accepted.

In Sect. 2 it was indicated that dialogue 1 should be intuitively evaluated as a partially successful persuasion and dialogue 2 as an over-successful persuasion. Below it is shown how the new definitions provide for partially and over-successful persuasion. Consider dialogue 1 again in which partially successful persuasion can be intuitively recognised: 
John_1 Please lend me a 100 euro note.

Ann_2 No, I can't. I have got only a 50 euro note.

John_3 OK, in that case I can take 50 euros.

Ann_4 OK.

Let's say that "Please lend me a 100 euro note" is a verbal manifestation of topic t. In this dialogue, topic $\mathrm{t}$ becomes a standpoint in move John_1 because the positive attitude to borrowing a 100 euro note from Ann is publicly expressed. If the definition of partially successful persuasion is to apply in this case, John and Ann need to agree on the version of topic $t$ generated by the implicature arising from the original standpoint of John and from a prototype topic from the BCM of John. The prototype topic needs to be activated in the mind of John by his manifest assumption. According to relevance theory, after move Ann_2 John creates in his mind the manifest assumption that Ann is willing to give 50 euros up to him. This manifest assumption is added to the cognitive environment of John and related to the BCM of John. If the manifest assumption agrees with a certain prototype topic from the BCM of John, then the prototype topic is activated. Assume that obtaining only 50 euros is a satisfying alternative for John, which means that it is the certain prototype topic belonging to the BCM of John. The manifest assumption that Ann is willing to give 50 euros up to John and the prototype topic that John wants to obtain 50 euros coincide with each other. The prototype topic activated by the manifest assumption is added to the information from the cognitive environment about the content of the standpoint of John and, in this way, the implicature is created in the mind of John that Ann should lend John a 50 euro note. The implicature is a version of original topic $t$. The agreement of both agents on the version of topic $t$ is achieved in move Ann_4 and the persuasion is thus partially successful for John. ${ }^{9}$ John will borrow less money but he will still get part of the amount he originally wanted.

Let us now consider dialogue 2 in which over-successful persuasion is achieved by agent $\mathrm{i}$ :

John_1 Please lend me 100 euros.

Ann_2 No I can't. I have got only a 200 euro note.

John_3 OK, in that case I can take 200 euros.

Ann_4 OK.

Let's say that "Please lend me a 100 euro note" is a verbal manifestation of topic t. In this dialogue, topic $t$ also becomes a standpoint in move John_1 because positive attitude to borrowing 100 euros from Ann is publicly expressed. According to the definition of over successful persuasion, John and Ann need to agree on the original standpoint and on the version of topic $t$ generated by the implicature arising from

\footnotetext{
${ }^{9}$ I agree with Paglieri and Castelfranchi (2010) that non-argumentative, extra-dialogical goals contribute to the final outcome of argumentation. Dialogical goals can only be a means for achieving extradialogical goals. For example, agent i might want agent i' to accept his standpoint "I think you should give a 100 euro note" to achieve an extra-dialogical goal of having another opportunity to meet agent i' when giving him back the money. Successfulness of dialogical goals should thus be considered with reference to successfulness of extra-dialogical goals. This paper is to be perceived as a first step towards a more comprehensive view of successfulness of an agent in a dialogue. Therefore, the focus here is on dialogical goals.
} 
the original standpoint of John and a prototype topic from the BCM of John. The prototype topic needs to be activated in the mind of John by his manifest assumption. According to relevance theory, after move Ann_2 John creates in his mind the manifest assumption that Ann wants to give him 200 euros. This manifest assumption is added to the cognitive environment of John and related to the BCM of John. If the manifest assumption agrees with a certain prototype topic from the $\mathrm{BCM}$ of John, then the prototype topic is activated. Assume that obtaining 200 euros is more satisfying for John than obtaining 100 euros. This means that the 200 euro acquisition is the certain prototype topic belonging to the BCM of John. The manifest assumption that Ann wants to give John 200 euros and the prototype topic that John wants to obtain 200 euros concur. The activated prototype topic is added to the information from the cognitive environment about the content of the standpoint of John and, in this way, the implicature is created in the mind of John that Ann should lend him a 200 euro note. The implicature is a version of original topic $t$. The agreement of both agents on the original standpoint and the version of topic $t$ is achieved in move Ann_4 since John will obtain what he originally wanted plus some extra money. Thus, the persuasion is over-successful.

As specified in the definition of partially-successful persuasion, the directionchange of topic $\mathrm{t}$ might have to do with logical implication or pragmatic implication. The pragmatic implication refers in the definition to accepting the implicit warrant of proponent's argument by an opponent. In dialogue 1, the implicit warrant of proponent's argument is accepted by an opponent. The implicit warrant of the reconstructed argument "You should give me a 100 euro note, because I need 100 euros and you have a 100 euro note" has the form "If Ann has a particular amount of money, then (within reasonable bounds) she should lend it to John, if he needs it". In dialogue 1, John has been able to employ this warrant in a successful way when advancing his second argument about the 50 euro note.

Consider dialogue 3 of partially successful persuasion which serves as an example explaining a direction-change of topic $\mathrm{t}$ based only on pragmatic implication:

John_1 Let's go to the cinema.

Ann_2 No, I don't feel like going to the cinema. But going to the theatre brings you closer to the culture as well.

John_3 OK, let's go to the theatre.

Ann_4 OK.

Assume that "Let's go to the cinema" is a verbal manifestation of topic $t$. In this dialogue, topic t of John becomes a standpoint in move John_1 because positive attitude to going to the cinema is publicly expressed. Move John_1 can be read also as expressive of a full argument "We should go to the cinema because it will bring me closer to the culture". The implicit warrant of the reconstructed argument has the form "If a cultural place brings me closer to the culture, then we should go to a cultural place". Ann, in move Ann_2, rejects the proposal of John to go to the cinema and expresses an argument in favour of going to the theatre. Simultaneously, in move Ann_2 she refers to the implicit warrant of John's argument in move 1. To meet the definition of partially successful persuasion, John and Ann need to agree 
on the version of topic $\mathrm{t}$ generated by the implicature arising from the original standpoint of John and from a prototype topic from the BCM of John. Assume that going to the theatre is a satisfying and allowable alternative for John, which means that it is a certain prototype topic belonging to the BCM of John. The implicature arising from the original standpoint and move Ann_2 is that Ann and John should go to the theatre. The implicature is a version of original topic t. The agreement of both agents on the version of topic t is achieved in move Ann_4 where Ann also accepts the implicit warrant of John's argument. The persuasion is thus partially successful.

\section{Some Features of Partial and Over-Successful Persuasion Dialogues}

In this section I will discuss two selected features of the partial and over-successful persuasion dialogues. The first one is concerned with the activation of a mental topic in the mind of agent $i$. The activation of a radial topic by a manifest assumption cannot contribute to partial and over-successful persuasion for agent i. The characteristic feature is thus the fact that only the activation of a prototype topic in the mind of agent $i$ might lead to those types of effects.

Thus, in the case of over-successful persuasion, obtaining more than agent $i$ has expected does not simply mean that over-success has been achieved by agent $i$. Consider dialogue 2 again in which a prototype topic is assumed to be activated in the mind of John:

John_1 Please lend me 100 euros.

Ann_2 No, I can't. I have got only a 200 euro note.

John_3 OK, in that case I can take 200 euros.

Ann_4 OK.

Observe that only if obtaining 200 euros is a prototype topic from the BCM of John (not a radial topic which belongs only to set Tjohn,t) will the implicature arising from move Ann_2 contribute to the over-successful outcome of the dialogue. If obtaining 200 euros was not a satisfying alternative for John (e.g., it would be a problem for him to carry in his wallet more than 100 euros), then it would be treated as a radial topic which would help John and Ann resolve the difference of opinion but not in John's favour. John's persuasive intention would not be realised.

The activated prototype topic needs to rely on the original topic $t$ and can change depending on a given dialogue. Assume that we have two dialogues to which the same $\mathrm{Ti}, \mathrm{t}$ of agent $\mathrm{i}$ involving the same topics $\{\mathrm{t} 1, \ldots, \mathrm{t} 10\}$ pertains. Depending on the content of topic $t$ and the nature of the conflict, agent $i$ will not consider the same topics equally satisfying in these two verbal exchanges. In one verbal exchange, topics $\{\mathrm{t} 1, \mathrm{t} 2, \mathrm{t} 3\}$ can be considered prototypical by agent $\mathrm{i}$ and other topics can be evaluated as radial. In a different verbal exchange, topics $\{t 2, t 10\}$ can be considered prototypical by agent $\mathrm{i}$ and other topics can be treated as radial. Thus, in the first verbal exchange the implicature needs to emerge from topics $\{t 1\}$ or $\{t 2\}$ or $\{\mathrm{t} 3\}$, and in the second verbal exchange from either topic $\{\mathrm{t} 2\}$ or topic $\{\mathrm{t} 10\}$, to produce a version of topic $t$ needed for partial and over-success. 
As for the second of these two features of partially and over-successful persuasion dialogues, this second feature pertains to the particular move in a dialogue which leads to the activation of a prototype topic. The activated prototype topic subsequently contributes to the generation of a version of topic through an implicature. The significant feature that characterises the move is the fact that the move might be expressed not only by the opponent of agent $\mathrm{i}$. The implicature might also arise after the prototype topic is activated by the move of the proponent of the original standpoint.

In dialogue 3 in the previous section, the prototype topic has been activated by the move of the opponent. In contrast, in dialogue 4 below, the prototype topic is activated by move John_3 of the proponent of the original standpoint:

Dialogue 4

John_1 I have said many times that I want a nuclear power station to be built in Poland.

Ann_2 I definitely don't want to have it in Poland. The government is considering building a nuclear power in Żarnowiec or Choczewo. These are highly populated areas. If a nuclear power exploded there, then it would pose a serious threat to the land on which the people live.

John_3 But there are restricted areas in Poland far away from the populated areas. Ann_4 OK, so let's built the nuclear power station in these non-populated, desolate areas in Poland.

Let's say that "I want a nuclear power station to be built in Poland" is a verbal manifestation of topic $t$. In this dialogue, topic t of John becomes a standpoint in move John_1 because the positive attitude to building a nuclear power station in Poland is publicly expressed. In move Ann_2, Ann expresses her negative opinion to topic $\mathrm{t}$ and presents an argument justifying her point. Assume that building a nuclear power station in a non-populated area is an allowable alternative for John to building the nuclear power station anywhere in Poland and therefore is a certain prototype topic belonging to the BCM of John. Assume that move John_3 of the proponent of the original standpoint leads to the activation of the prototype topic through the manifest fact that there are restricted areas in Poland far away from the populated areas. Thus, in this dialogue, the move of the proponent of the original standpoint, not the move of the opponent as was the case in dialogues $1-3$, leads to the activation of the prototype topic in the proponent's mind.

\section{Conclusion}

The main aim of this paper was to offer a supplementary model which provides for two types of effects of persuasion: partially successful dialogue and over-successful dialogue. The proposed model introduces the notion of a modified version of the original topic $t$ which helps to define these two types of effects of the persuasive force of argument. It has been indicated in what way three relevance-theoretic notions of cognitive environment, manifest assumption and implicature contribute 
to the explanation of the processes of the generation of the modified version of topic t. I have introduced what I have called the BCM. It comprises prototype topics which need to be activated by a manifest assumption to produce an implicature acting as the modified version of topic t. BCMi,t has been defined as a mental model belonging to the cognitive environment of agent $i$ which consists of a set of prototype topics which help agent i resolve the conflict of opinion but only in his favour. It has been shown that the activation of a prototype topic from a BCMi,t by the move of agent $\mathrm{i}$ or his opponent provides for the discussion of the directionchange of topic $\mathrm{t}$ based on the logical or pragmatic implication.

Open Access This article is distributed under the terms of the Creative Commons Attribution License which permits any use, distribution, and reproduction in any medium, provided the original author(s) and the source are credited.

\section{References}

Aristotle. 1955. The organon. Vol. 1: Prior analytics. (Translated by Harold P. Cooke and Hugh Tredennick; 1st standard edition in Greek by Andronicus of Rhodes, 1st century B.C.) Cambridge, Mass.: Harvard University Press.

Aristotle. 1959. The art of rhetoric. (Translated by John Henry Freese; 1st standard edition in Greek by Andronicus of Rhodes, 1st century B.C.). Cambridge, Mass.: Harvard University Press.

Budzynska, Katarzyna, and Magdalena Kacprzak. 2008. A logic for reasoning about persuasion. Fundamenta Informaticae 85: 51-65.

Budzynska, Katarzyna, and Magdalena Kacprzak. 2011. Model checking of persuasion in multi-agent systems. In Studies in logic, grammar and rhetoric, special issue on argument and computation, vol. 23, ed. M. Koszowy, 99-122.

Budzynska, Katarzyna, and Kamila Debowska. 2010. Dialogues with conflict resolution: Goals and effects. In Aspects of semantics and pragmatics of dialogue, ed. Pawel Lupkowski, and Mathew Purver, 59-66. Poznan: Polish Society for Cognitive Science.

Budzynska, Katarzyna and Maciej Witek. 2014. Non-Inferential Aspects of Ad Hominem and Ad Baculum. In Argumentation, special issue "The Polish School of Argumentation", vol. 3, eds. K. Budzynska and M. Koszowy. doi:10.1007/s10503-014-9322-6.

Cap, Piotr. 2010. Pragmatics, micropragmatics macropragmatics. Lodz Papers in Pragmatics 6(2): 195-228.

Carston, Robyn. 2002. Thoughts and utterances: The pragmatics of explicit communication. Oxford: Blackwell.

Castelfranchi, Cristiano, and Fabio Paglieri. 2007. The role of beliefs in goal dynamics: Prolegomena to a constructive theory of intentions. Synthese 155: 237-263.

Debowska, Kamila, Paweł Łoziński, and Chris Reed. 2009. Building bridges between everyday argument and formal representations of reasoning. In Studies in logic, grammar and rhetoric, special issue on informal logic and argumentation theory, vol. 16, ed. M. Koszowy, 95-135.

Garssen, Bart. 2001. Argument Schemes. In Crucial concepts in argumentation theory, ed. F.H. van Eemeren, 81-99. Amsterdam: Amsterdam University Press.

Grice, Paul Herbert. 1989. Studies in the way of words. Cambridge, MA: Harvard University Press.

Grice, Paul Herbert. 1975. Logic and conversation. In Syntax and semantics. Vol. 3: Speech acts, ed. P. Cole, and J. Morgan, 41-58. New York: Academic Press.

Hamblin, Charles L. 1970. Fallacies. London: Methuen. [Reprinted, 1993], Virginia: Vale Press.

Houtlosser, Peter. 2001. Points of view. In Crucial concepts in argumentation theory, ed. F.H. van Eemeren, 27-50. Amsterdam: Amsterdam University Press.

Kacprzak, M., and O. Yaskorska. 2014. Dialogue Protocols for Formal Fallacies. In Argumentation, special issue "The Polish School of Argumentation", vol. 3, eds. K. Budzynska and M. Koszowy. doi:10.1007/s10503-014-9324-4.

Katriel, Tamar, and Marcelo Dascal. 1989. Speaker's commitment and involvement in discourse. In From sign to text: A semiotic view of communication, ed. Yishai Tobin, 275-295. Amsterdam: John Benjamins. 
Kopytko, Roman. 2002. The mental aspects of pragmatic theory. Poznan: Motivex.

Lakoff, George. 1987. Women, fire, and dangerous things. Chicago: University of Chicago Press.

O'Keefe, Daniel J. 2002. Persuasion: Theory and research. Thousand Oaks, California: Sage Publications.

Paglieri, Fabio, and Castelfranchi Cristiano. 2010. Why arguing? Towards a costs-benefits analysis of argumentation. Argument and Computation 1: 71-91.

Perelman, Chaim and Lucie Olbrechts-Tyteca. 1969. The new rhetoric: A treatise on argumentation. (Translated by John Wilkinson-Purcell Weaver.) Notre Dame: University of Notre Dame Press.

Rigotti, Eddo. 2007. Can classical topics be revived within the contemporary theory of argumentation? In Proceedings of the sixth conference of the international society for the study of argumentation. 1155-1163. Amsterdam: Sic Sat.

Rigotti, Eddo, and Sara Greco Morasso. 2010. Comparing the argumentum model of topics to other contemporary approaches to argument schemes: the procedural and material components. Argumentation 24: 489-512.

Searle, John. 1970. Speech acts: An essay in the philosophy of language. Cambridge: Cambridge University Press.

Sperber, Dan, and Deirdre Wilson. 1986. Relevance: Communication and cognition. Oxford: Blackwell.

van Eemeren, Frans H. 2001. The state of art in argumentation theory. In Crucial concepts in argumentation theory, ed. Frans H. van Eemeren, 11-26. Amsterdam: Amsterdam University Press.

van Eemeren, Frans H. 2009. Strategic Manoeuvring Between Rhetorical Effectiveness and Dialectical Reasonableness, In Studies in logic, grammar and rhetoric, special issue "informal logic and argumentation theory", vol. 16, ed. M. Koszowy, 69-91.

van Eemeren, Frans H., and Rob Grootendorst. 1984. Speech acts in argumentative discussions. Dordrecht: Foris Publications.

van Eemeren, Frans H., and Rob Grootendorst. 1992. Argumentation, communication, and fallacies. A pragma-dialectical perspective. Hillsdale, NJ: Lawrence Erlbaum Associates.

van Eemeren, Frans H., and Rob Grootendorst. 2004. A Systematic theory of argumentation: The pragmadialectical approach. Cambridge: Cambridge University Press.

van Eemeren, Frans H., and Peter Houtlosser. 2000. Rhetorical analysis within a pragma-dialectical framework. Argumentation 14(3): 293-305.

van Eemeren, Frans H., and Peter Houtlosser. 2002. Strategic maneuvering with the burden of proof. In Advances in pragma- dialectics, ed. F.H. van Eemeren, 13-27. Amsterdam: Sic Sat.

van Eemeren, Frans H. and Peter Houtlosser. 2004. A pragma-dialectical analysis of the burden of proof. [Unpublished seminar paper. University of Amsterdam: Department of Speech Communication, Argumentation Theory and Rhetoric].

van Eemeren, Frans H., Rob Grootendorst, Sally Jackson, and Scott Jacobs. 1993. Reconstructing argumentative discourse. Tucaloosa: University of Alabama Press.

Walaszewska, Ewa, and Agnieszka Piskorska 2012. Relevance theory: More than understanding. Newcastle Upon Tyne: Cambridge Scholars Publishing.

Walton, Douglas. 1995. A pragmatic theory of fallacy. Tuscaloosa: University of Alabama Press.

Walton, Douglas, and Erik Krabbe. 1995. Commitment in dialogue: Basic concepts of interpersonal reasoning. Albany, New York : State University of New York. Press.

Wilson, Deirdre. 1994. Relevance and understanding. In Language and understanding, ed. Gillian Brown, Kirsten Malmkjær, Alastair Pollitt, and John Williams, 35-58. Oxford: Oxford University Press.

Wilson, Deirdre. 2000. Metarepresentation in linguistic communication. In Metarepresentations: $A$ multidisciplinary perspective, ed. D. Sperber, 411-448. Oxford: Oxford University Press.

Wilson, Deirdre, and Dan Sperber. 2006. Relevance theory. In The handbook of pragmatics (2nd edition, 1st edition 2004.), ed. L.R. Horn, and G. Ward, 607-632. Malden: Blackwell Publishing.

Yus, Francisco. 2006. Relevance theory. In Encyclopedia of language and linguistics, ed. Keith Brown, 512-519. Oxford: Elsevier. 